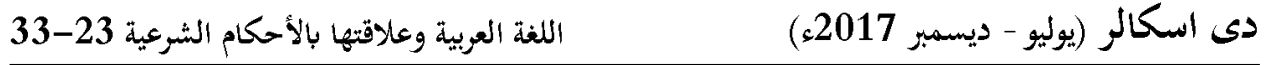

$$
\begin{aligned}
& \text { اللغة العربية وعلاقتها بالأحكام الثرعية }
\end{aligned}
$$

\title{
ARABIC -ARABIC LANGUAGE AND ITS RELATION WITH ISLAMIC COMMANDMENTS
}

\author{
Dr.Abdul Majeed Baghdadi*, Dr. Muhammad Saleem ${ }^{* *}$ \\ The Scholar Islamic Academic Research Journal || Web: www.siarj.com \| \\ P. ISSN: 2413-7480 || Vol. 3, No. 2 || June-December 2017 || P. 23-33 \\ DOI: $10.29370 /$ siarj/issue5ar9 \\ URL: https://doi.org/10.29370/siarj/issue5ar9 \\ License: Copyright c 2017 NC-SA 4.0
}

\begin{abstract}
:
Linguists and Muslim jurists have depended heavily on the Arabic Language in their researches about Islamic legislation. The Arabic language is the true method of understanding the words of Holy Quran which is the first reference in deriving Islamic Commandments. Without learning and understanding the Arabic Language it is impossible to get knowledge of Islamic legislation, therefore, the Muslim has started to teach and learn the Arabic Language. The jurists have made it the basic condition to derive the Islamic Commandments for interpretation. The Companions of Holy Prophet (PBUH) and their followers have struggled for the interpretation of Holy Quran as linguistic explanation. This research will present the importance of Arabic Language in the light of Quran, Șünnāh and conduct of Companions and İmāmṣ. In this research the importance and necessity of Arabic Language has been included according to the opinion of jurists and imams for interpreters and Muftis. This study will strengthen the relationship between Arabic Language and Islamic Commandments and it will increase the passion to learn the Arabic Language.
\end{abstract}

KEYWORDS: Linguists, Muslim jurists, Islamic legislation, Arabic

\footnotetext{
*Assistant Professor, Department of Arabic, Allamah Iqbal Open University, Islamabad, Email:baghdadidgk@gmail.com

** Assistant Professor, Department of Islamic Studies, Mohi-ud-Din Islamic University, Nerian Shareef,AJ\&K, Email:hafizmuhammadsaleemsaeedi@hotmail.com
} 
Language, Holy Prophet, Ṣūnnāḥ, Īmāmṣ.

الكلمات المفتاحية: اللغويين، الفقهاء المسلمبن، التشريع الإسلامي، اللغة العربية، النبي الكريم،

السنة، الأئمة.

أ) أملدخل:

إن اللغة العربية هي الطريق السليم لفهم ألفاظ القرآن ومعانيه فهماً حقيقياً، والقرآن الكريم هو المصدر

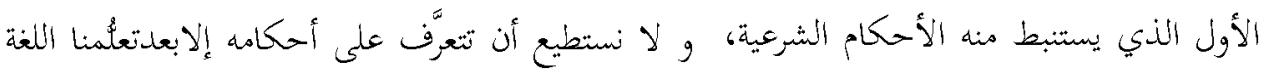

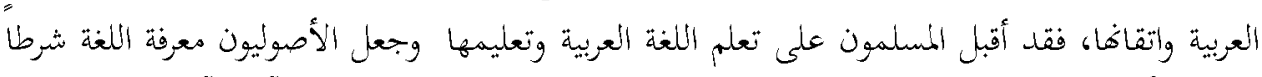

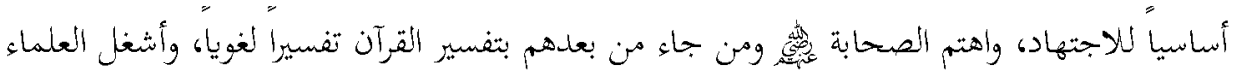

حيزا كبيرا من مؤلفاتم في بيان العلاقة بين الشريعة والعربية.

\section{اللغة العربية في ضوء القرآن والسنة:}

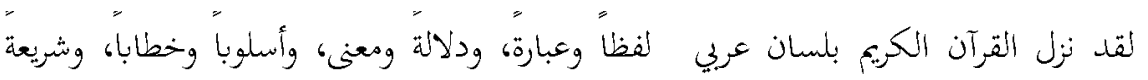

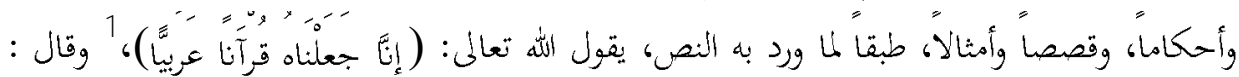

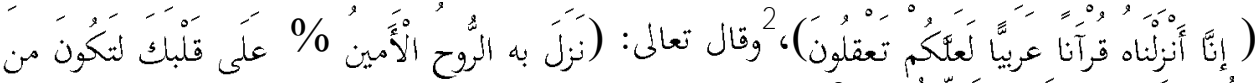

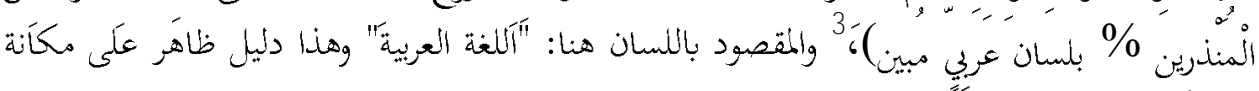

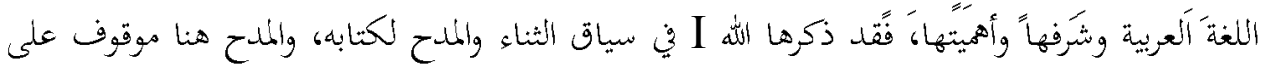

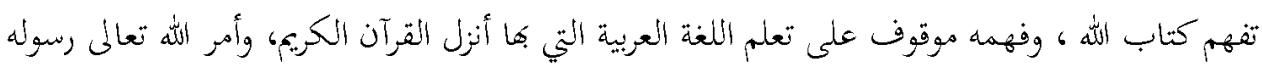

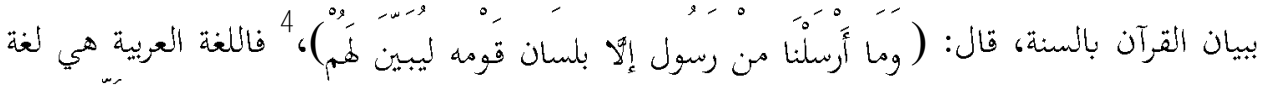

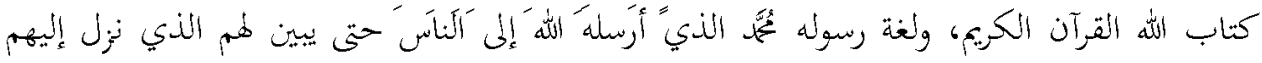

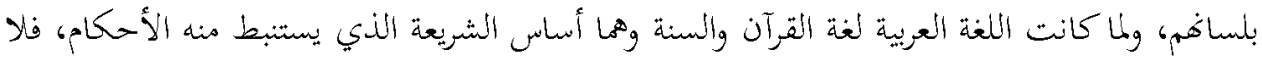

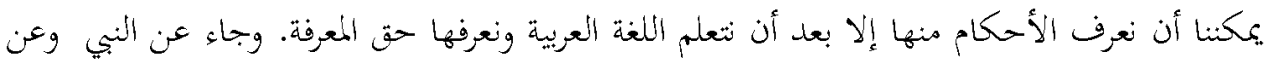

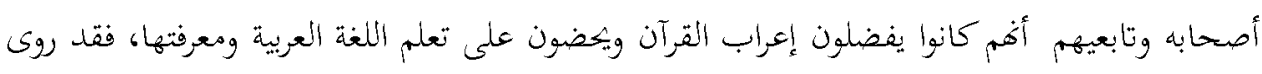

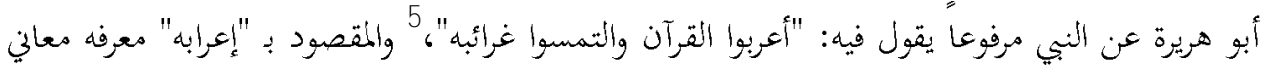

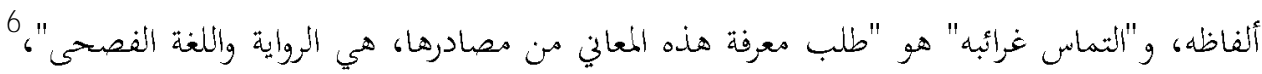

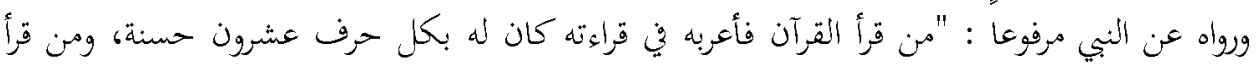

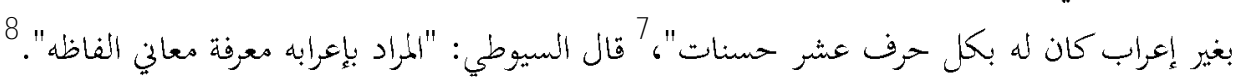

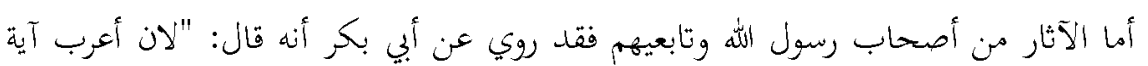


أحب إليَّ من أن أحفظ آية"، وروي عن أبي ذر قوله: "تعلموا العربية في القرآن كما تتعلمون

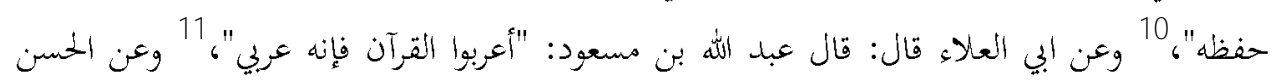

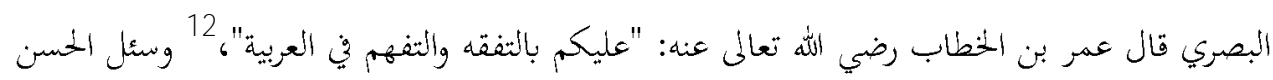

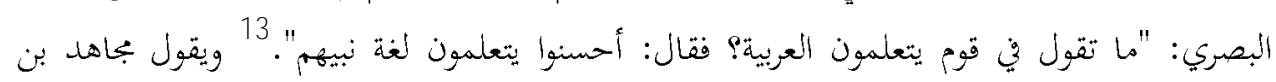

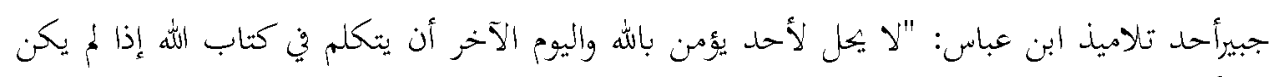
عالماً بلغات العرب". 14

\section{ب) معرفة اللغة عند الائمة والفقهاء:}

نذكر كما يلي أقوال الأئمة والفقهاء في أهمية اللغة العربية، بعضهم يطلقون على وجوب تعلم

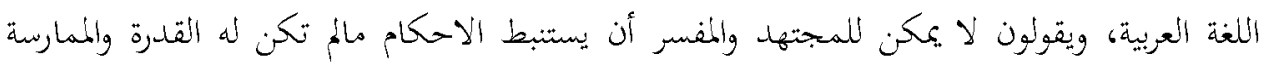

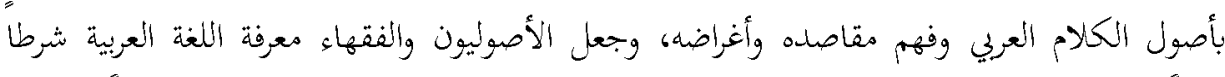

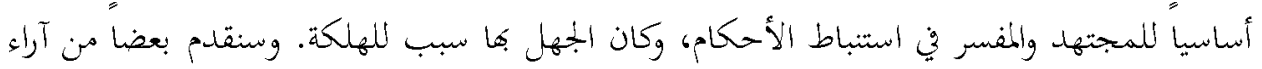
الأئمة والفقهاء حول هذا الموقف: أشار الإمام ابن تيمية إلى أهمية تعلم اللغة العربية في كثير من المواضع، فقد نص "على أن اللغة العربية من الدين، ومعرفتها فرض وواجب لأن فهم الكتاب والسنة لا يتم إلا بفهمها"، 15 فقد قال

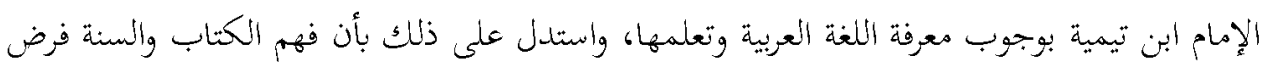

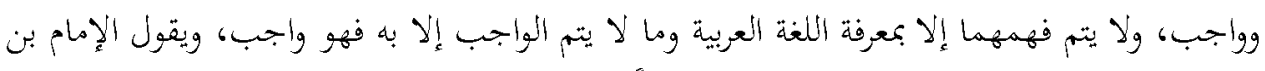

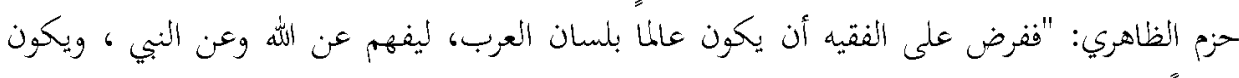

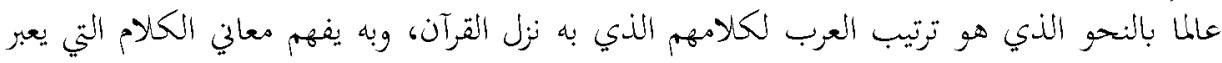

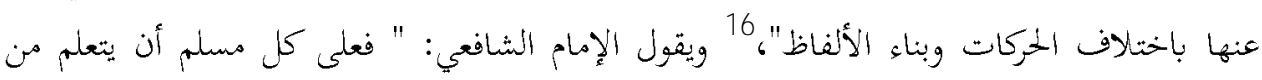

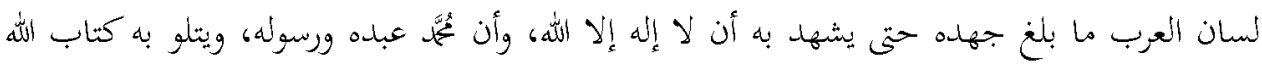

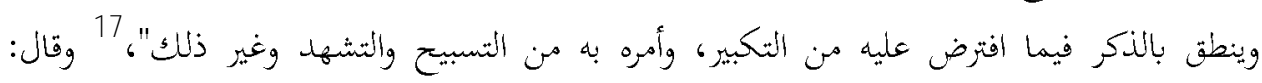

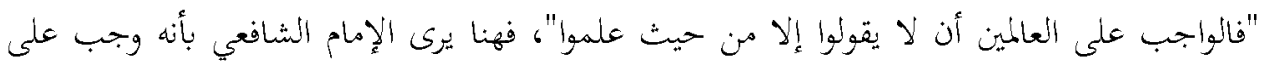

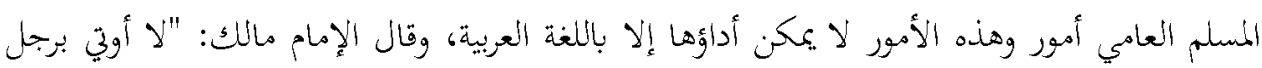

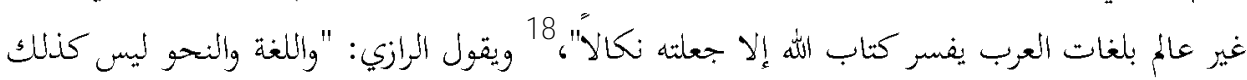

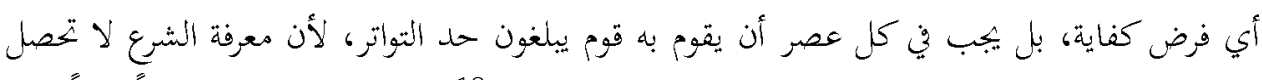
إلا بواسطة هعرفة اللغة والنحو، والعلم بهما إلا النقل المتواتر"، 19 وقد أورد الشاطبي تنبيهاً هامأ بأن:

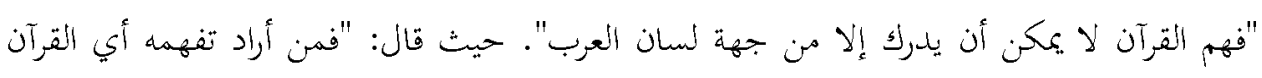


فمن جهة لسان العرب يفهم ولا سبيل إلى تطلب فهمه من غير هذه الجهة"، وقوقال : "وهو فرض علم

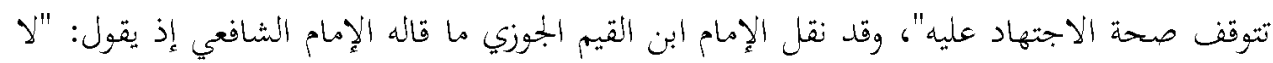

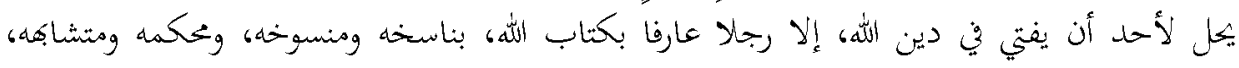

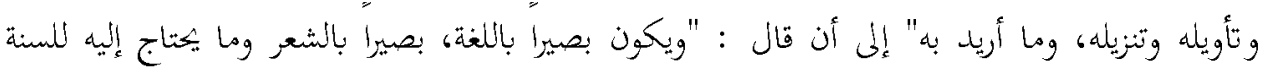

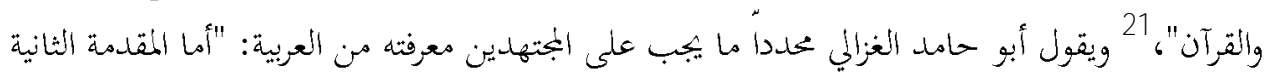

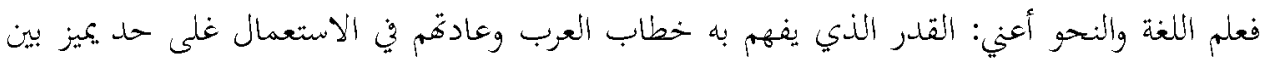

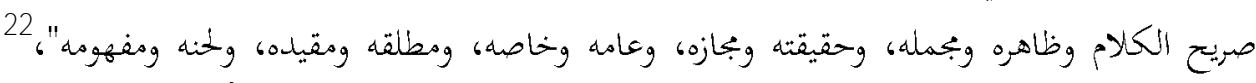

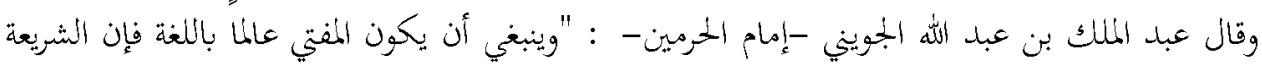

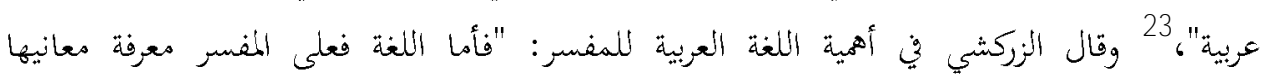

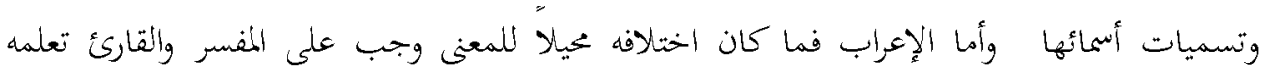

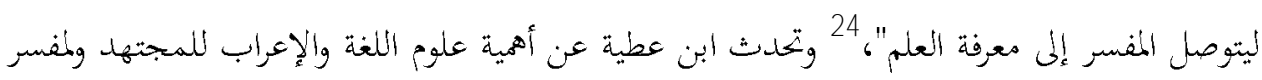

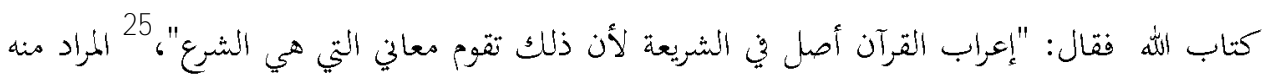

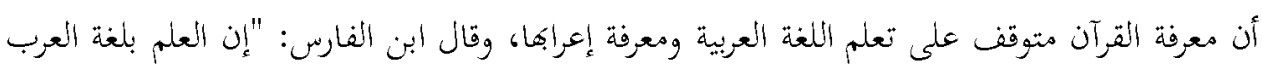

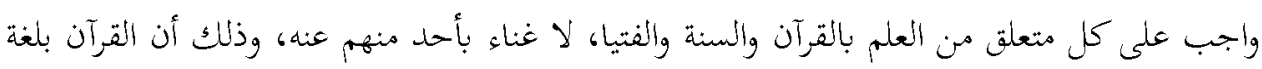

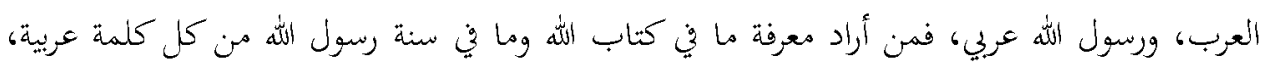

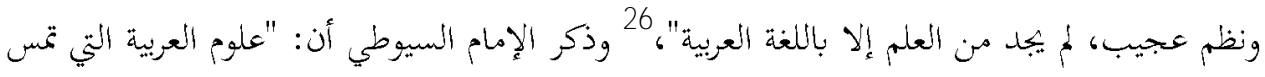

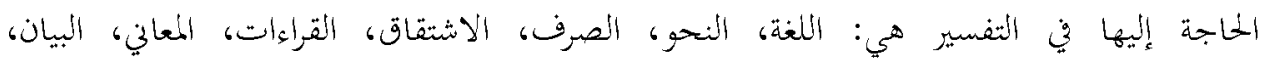

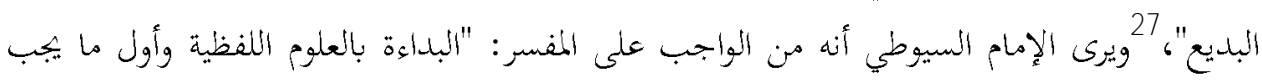

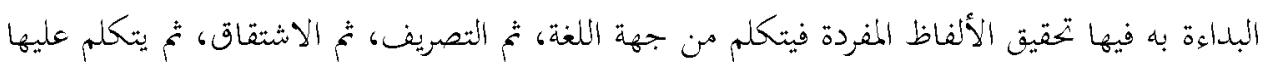

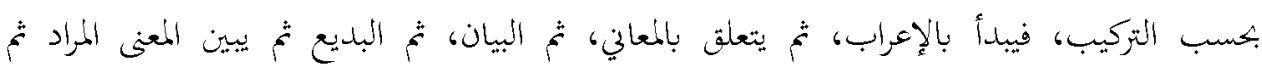

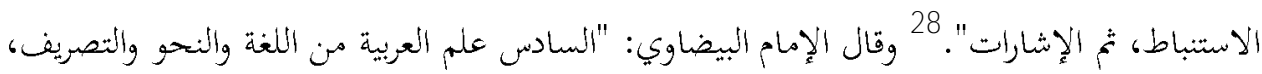

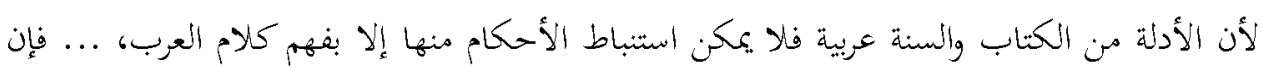

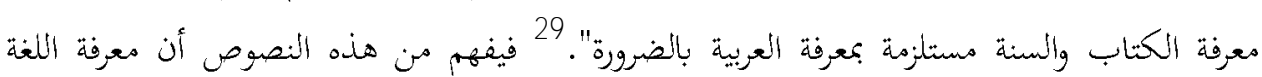

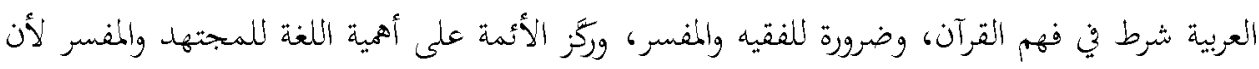

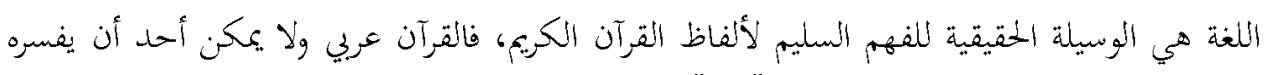

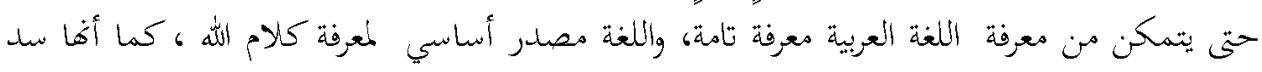

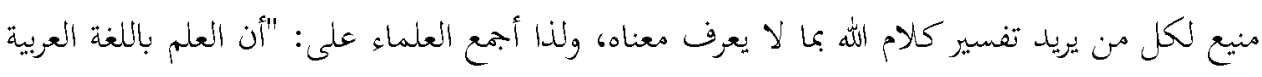


وآدابها شرط أساسي من شروط المفسر والمجتهل، وفهم القرآن والسنة فرض، ولا يفهم إلا بفهم اللغة

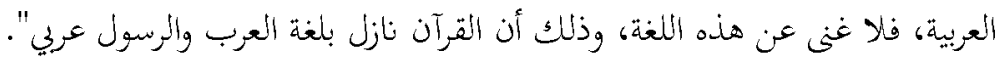

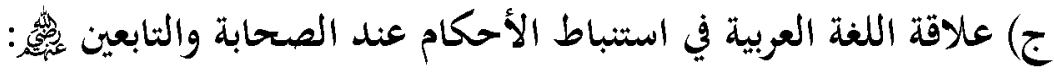

كان الصحابة يعودون إلى لغتهم العربية عند بياهم للقرآن، فكانت اللغة أحد مصادرهم

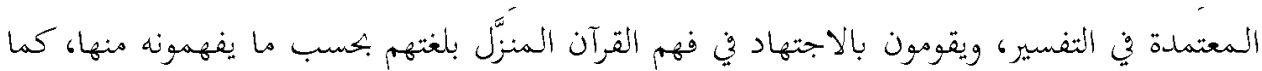

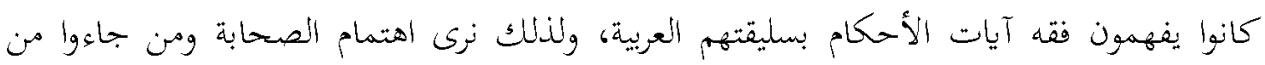

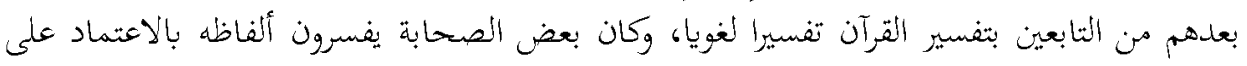

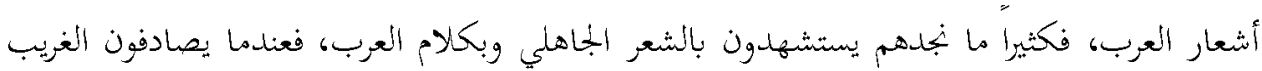

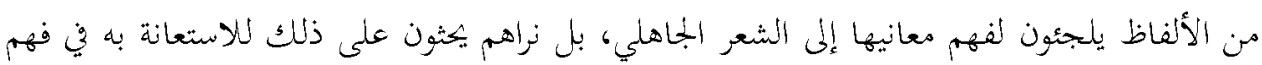

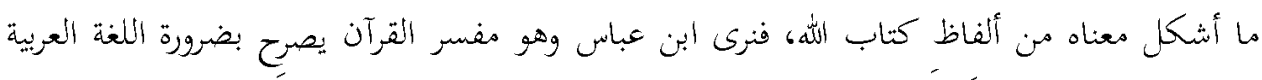

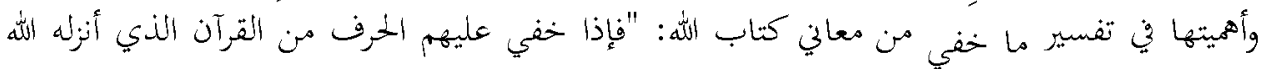

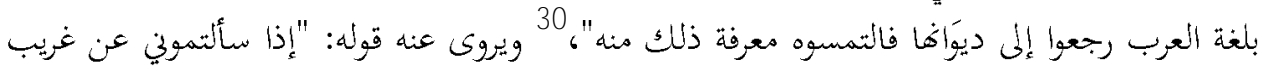

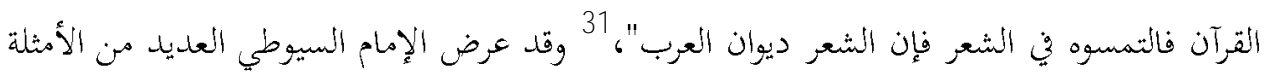

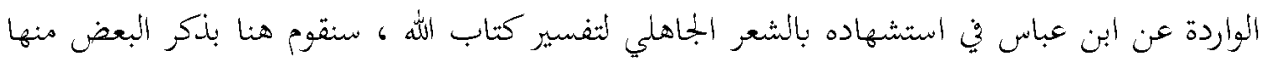

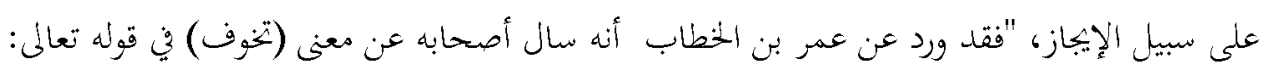

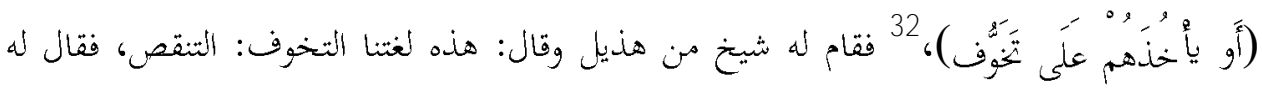

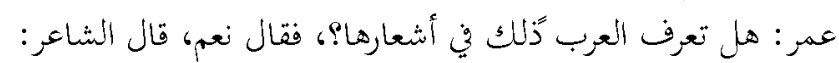

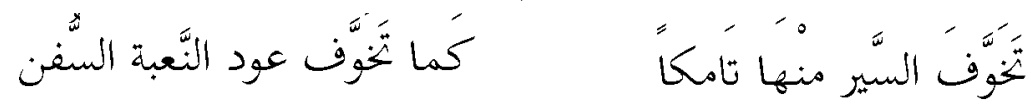

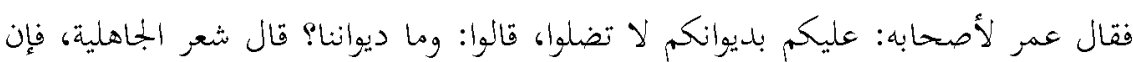

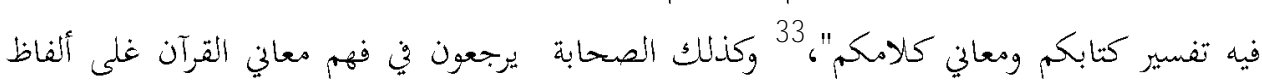

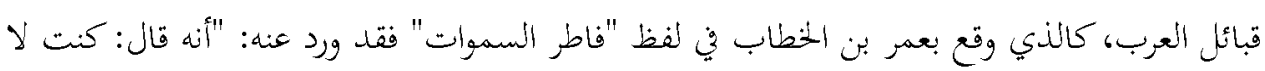

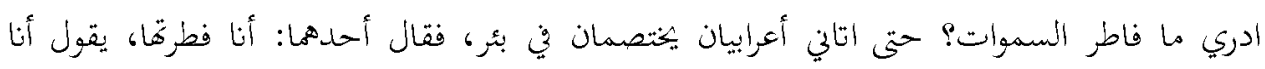

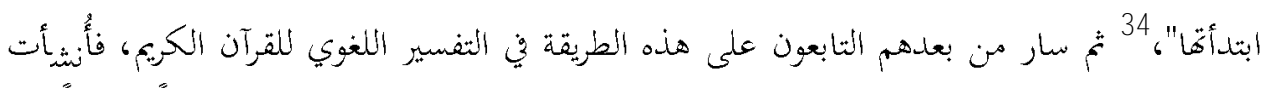

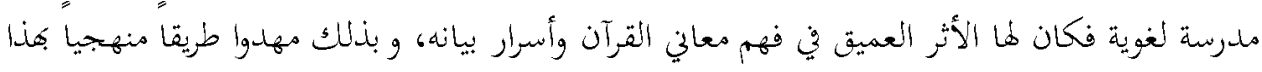

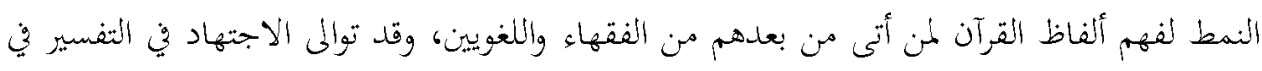

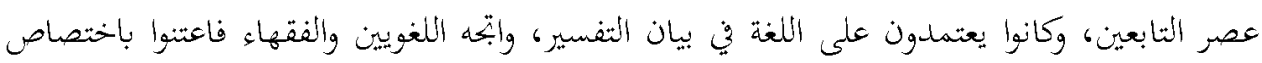


القرآن الكريم في تحدثهم عن لغنه، وإعرابه، وتحليل هعانيه، وألفوا التصانيف لمعاني القرآن ولإعرابه،

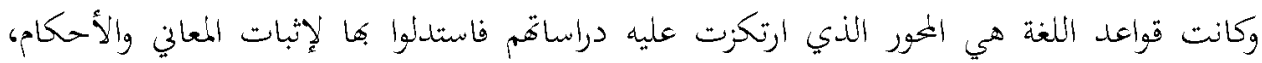

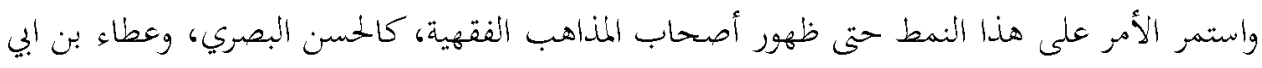
رباح، وإبراهيم النتعي وغيرهم.

\section{د) علاقة اللغة العربية في استنباط الأحكام عند الفئه الفهاء:}

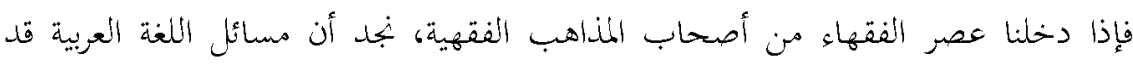

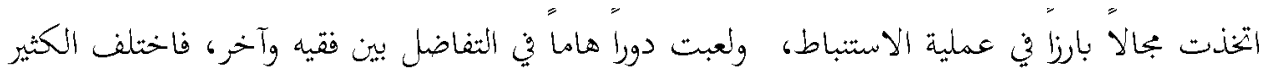

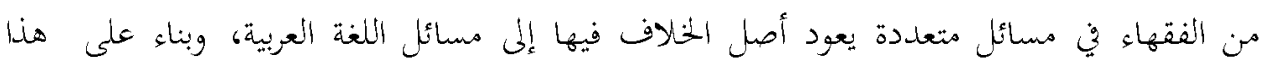

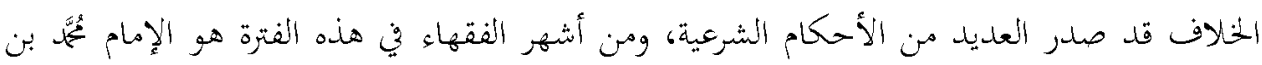

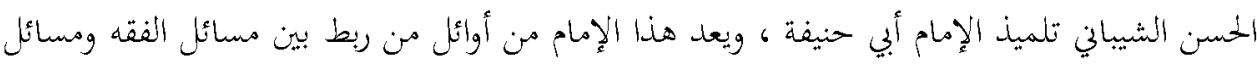

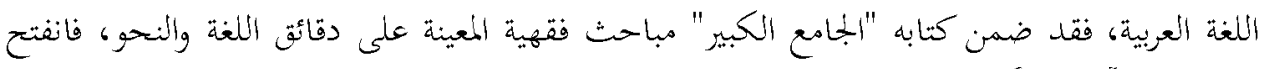
بذلك ميداناً شاسعاً من ميادين التأمل في النفاعل بين الأحكام الشرعية واللغة العربية.

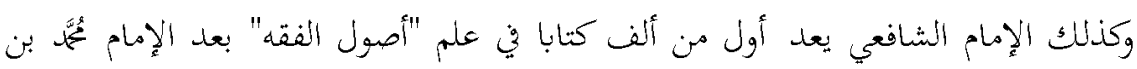
الحسن وسماه "الرسالة"، وقد تحدث فيه الإمام الشافعي عن ارتباط اللغة العربية وعلاقتها بالأدلة

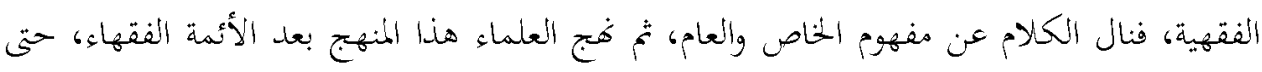

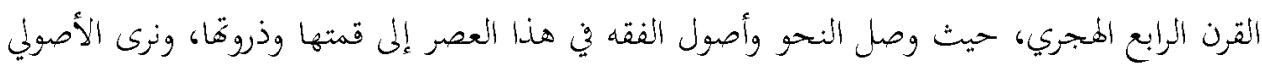

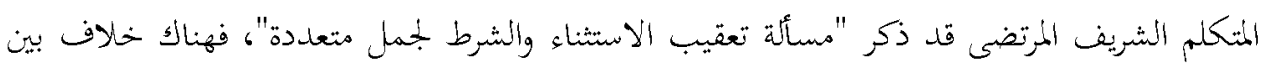

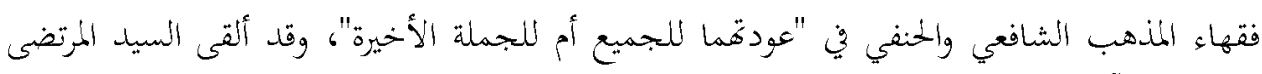

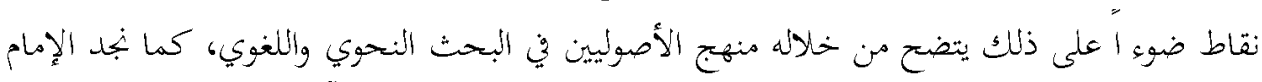

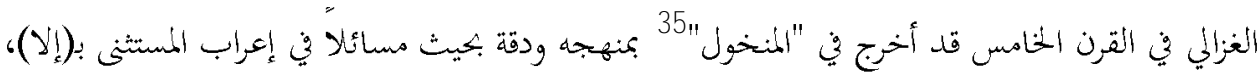

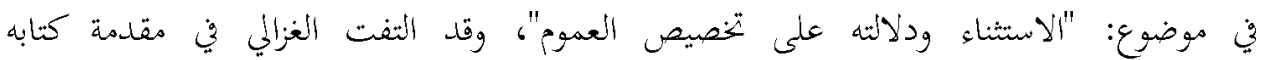
"المُستصفى" "36 إلى مسائل كثيرة بين الدلالات اللغوية والأحكام الشرعية فذكر فيه من معاني الخروف

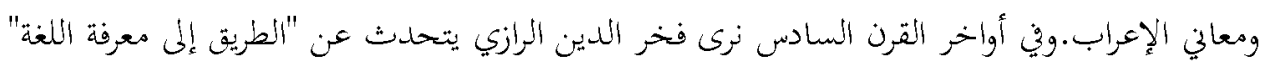

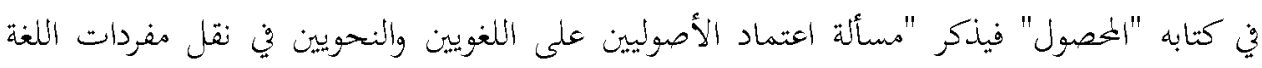
والنحو ".

و نرى في القرن الثامن الأصولي أبي إسحاق الشاطبي قد أظهر على الناس كتابه "الموافقات"

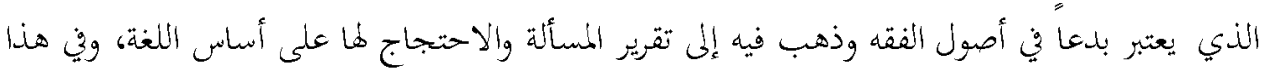


القرن الثامن تناول جمال الدين عبد الرحيم بن الحسن الأسنوي في كتابيه "التمهيد في تخريج الفروع على لئ

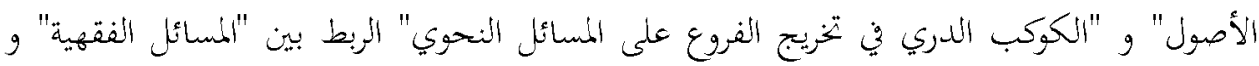

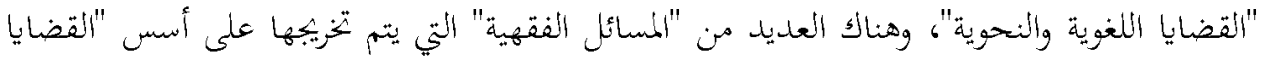
37 اللغوية والنحوية. 37

\section{هـ ) اللغة العربية وعلاقتها بالأحكام الثرعية:}

إن العلاقة بين "اللغة العربية" و "الأحكام الشرعية" علاقة وثيقة وعميقة لا انفصام هلا، فالنصوص الشرعية وردت في اللغة العربية، وكان البعض من هذه النصوص "ظنية الندلالة"، فقام العلماء

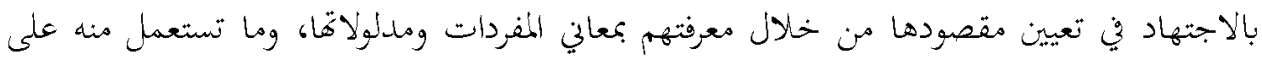

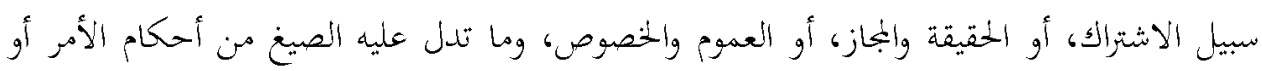

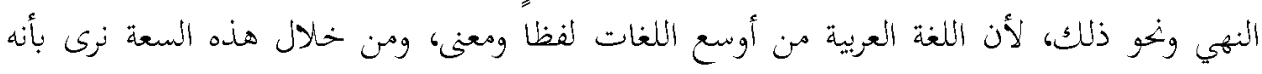

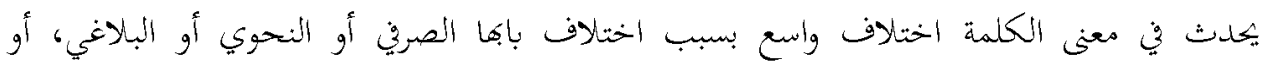

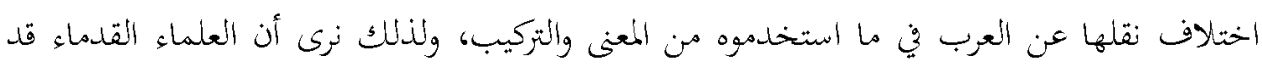

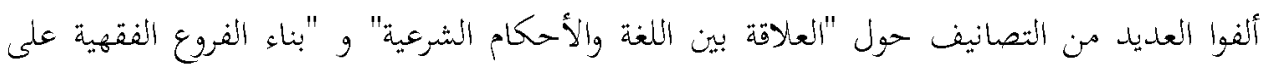
القواعد العربية".

\section{علاقة علم النحو بالأحكام:}

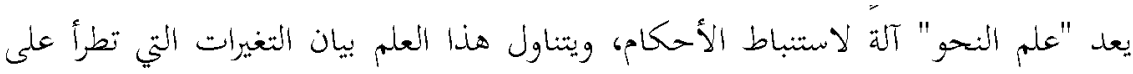

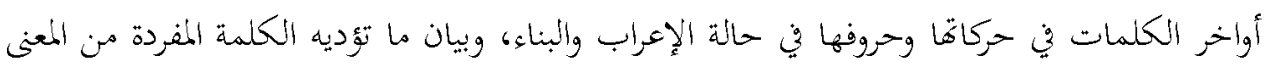

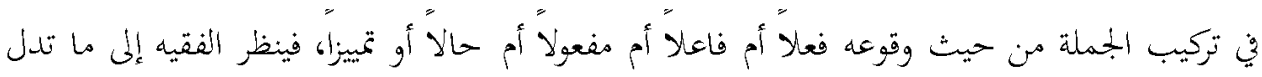

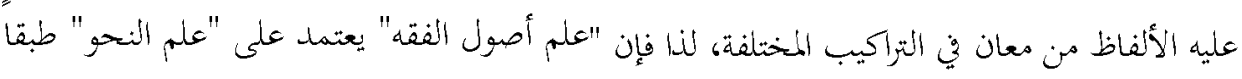

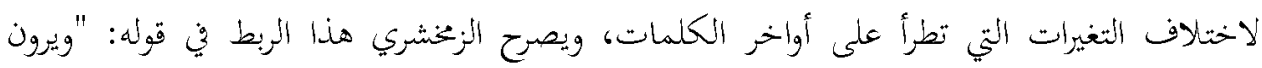

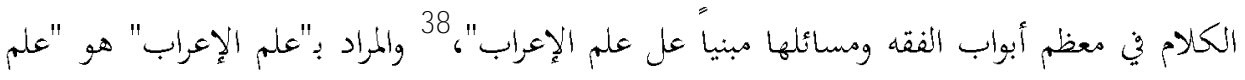

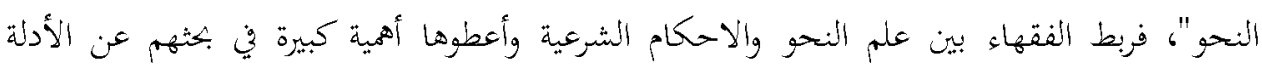

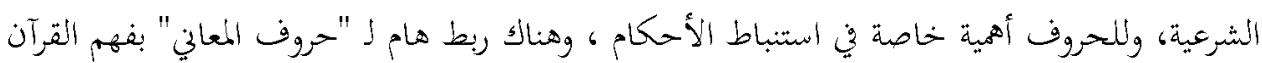

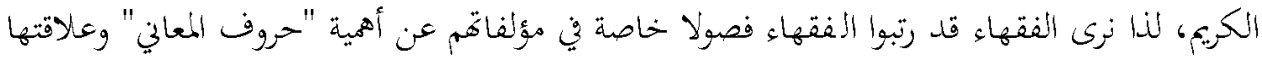

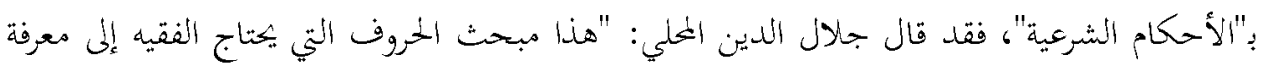

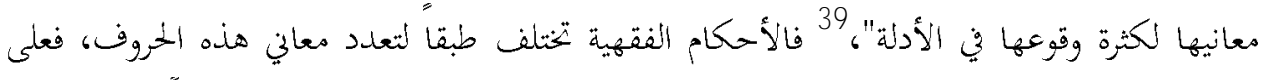

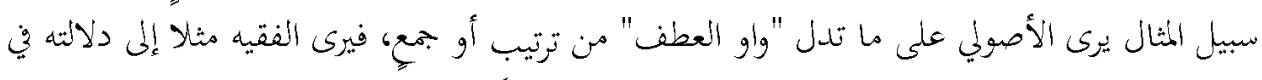


آية الوضوء على وجوب الترتيب في غسل الأعضاء أو عدم وجوبه. علاقة علم الصرف بالأحكام الثرعية:

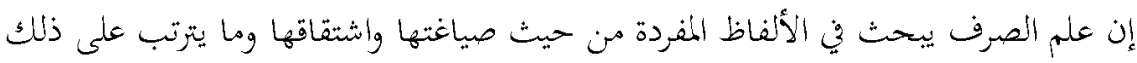

من تغيير في معانيها، فنرى الفقهاء قد اختلفوا في بعض المسائل الفقهية بناء على صيغ الألفاظ

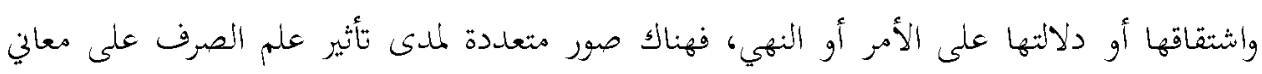

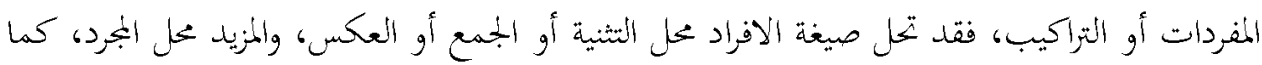

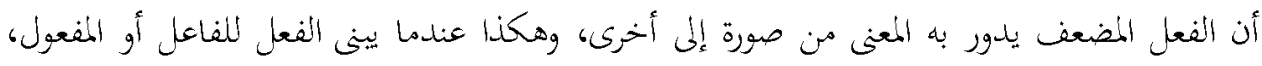

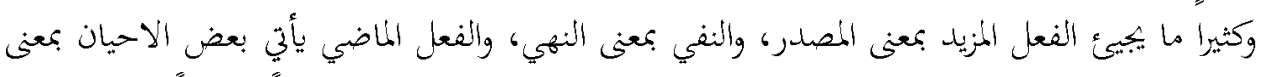

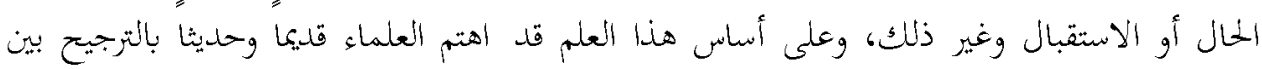
المسائل الشرعية.

\section{علاقة القواعد البلاغية بالأحكام الثرعية:}

لقد تناول الأصوليون أغلب الأبحاث البلاغية بالبحث في أصول الفقه، لأن معظم نظر الأصولي يكون في دلالات الألفاظ كالحقيقة أو المجاز، والعموم أو الخصوص، والألفاظ المشركة، والمعرفة

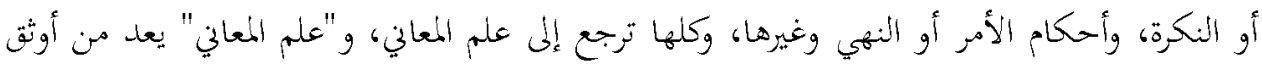

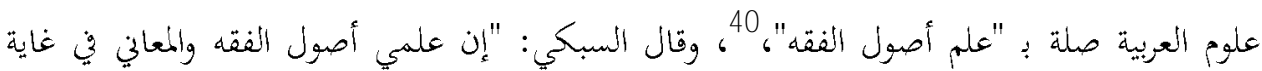
التداخل."

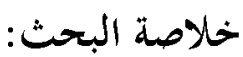

بناء على أساس اللغة العربية، قد استنتجنا في هذا البحث عن مكانة اللغة العربية وأهميتها في

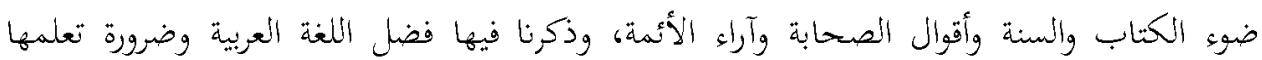

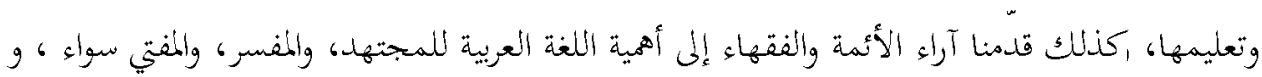

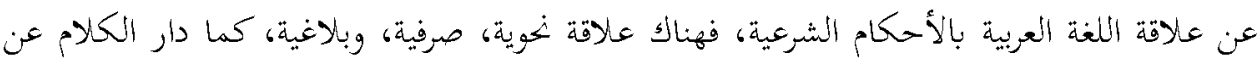

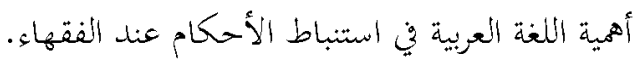

\section{(1)(0)}

BY NC SA This work is licensed under a Creative Commons Attribution-NonCommercial-ShareAlike 4.0 International (CC BY-NC-SA 4.0) 


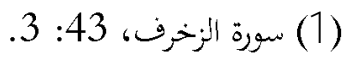

(2) سورة يوسف، 12: 3.

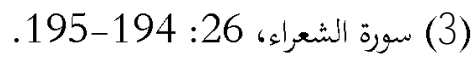

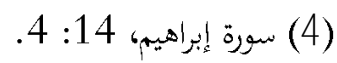

(5) الجامع الصغير في حديث البشير النذير: جـلال الدين عبد الرممن أبوبكر السيوطي، ج/1، ص/39،

1321هـ، مطبعة الميمنة، مصر، وبجمع الزوائد: للإمام الهيثمي، باب فضل القرآن، ج/7، ص/163، ط/3،

1402هـ، دار الكتاب العري، بيروت، وفضائل القرآن: لابن كثير، ص/201، 1347هـ، تصحيح وتعليق:

كيمّة رشيد رضا، مطبعة المنار، مصر.

(6) مقدمة صفوة التفسير: للشيخ حسنين يُجة مخلفف، ص/ ، ط/3، 1407هـ، وزارة الأوقاف، الكويت. (7) شعب الإيمان: للإمام البيهقي، ج/3، ص/428، ط/1401، 1401، دار الكتب العلمية، بيروت.

(8) الإتقان في علوم القرآن: للسيوطي، ج/2، ص/3، 1368ه، مطبع الحجازي، القاهرة.

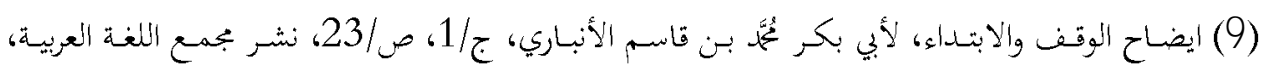

دمشق.

(10) (المصدر السابق، ص/23.

(11) نضائل القرآن: لأبي عبيد، ص/99، ط/، 1411ه، دار الكتب العلمية، بيروت.

(12) (12) المصدر السابق، ص/99.

(13) الصعقة الغضبية: لأبي الربيع سليمان الطوفي، ص/233، ط/1، 1417هـ، دار العبيكان.

(14) إيضاح الوقف والابتداء: لابن الانباري، ص/39، والصعقة الغضبية: للطوفي، ص/248.

(15) اتضاء الصراط المستقيم: لابن تيمية، ج/1، ص/469، تحقيق: ناصر بن عبد الكريع العقل، مكتبة

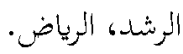


(16) الإحكام في اصول الأحكام: لعلي بن أممد بن سعيد بن حزم الظطري، ج/2، ص/693، مطبعة

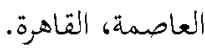

(17) الرسالة: للإمام الشانعي، فقرة/167، ص/48، تحتيق: أممد شاكر، طبعة دار الفكر، دمشق.

$$
\text { (18) شعب الإمان: للبيهقي، ج/2، ص/425. }
$$

(19) الخصول في أصول الفقه: لحمد بن عمر الرازي، ج/6، ص/35، ط/2، 1412هـ، تحقيق: طه جابر

$$
\text { فياض العلواني. }
$$

(20) الموافقـات: لإبراهيم بن موسى الشاطبي، ج/2، ص/102، ط/10 تحقيق: مشهور بن حسـن آل

(21) أعلام الموقعين عن رب العالمين: لابن القيم الجوزي ثُحّة بن أبي بكر، ج/1، ص/46، 1948م، مطبعة

السعادة، مصر، البحث النحوي عند الأصوليين: لمصطفى جمال الدين، ص/45، ط/205، 1405هـ، من

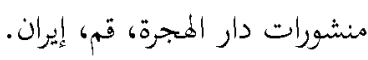

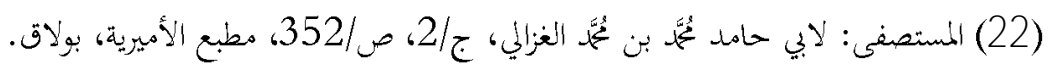

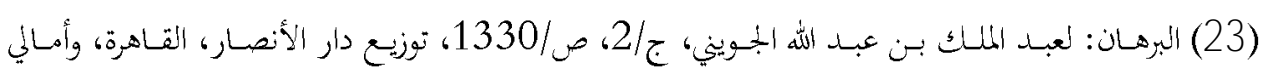

الدلالات وبحالات الاختلافات: للشيخ عبدالله، ص/360، دار الناشر ابن حزم، مكتبة مكية.

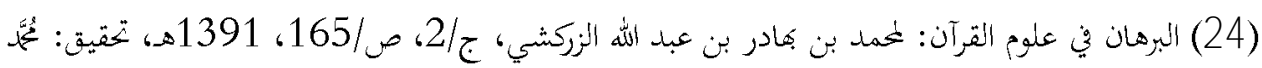

$$
\text { أبو الفضل إبراهيم، طبع دار المعرفة، بيروت. }
$$

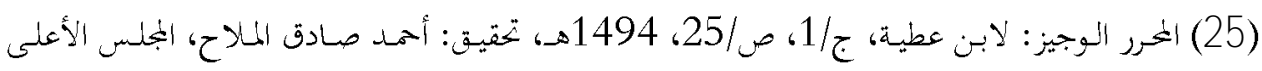

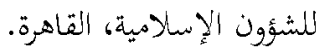

(26) الصاحبي في فقه اللغة: لابن فارس، ص/5، تحقيق: السيد أممد صقر، مكتبة البابي الحلبي، القاهرة.

$$
\text { (27) التبحير في علم التفسير: للسيوطي، ص/41، دار الكتب المصرية. }
$$


(28) الإتقان في علوم القرآن: للسيوطي، ج/3، ص/222، ط/5، 1422هـ.

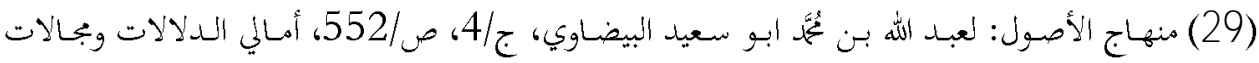

الاختلافات، للشيخ عبد الله، ص/37.

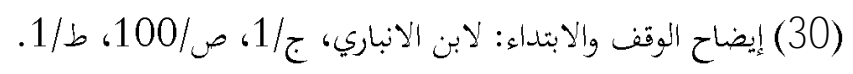

(31) الإتقان في علوم القرآن: للسيوطي، ج/1، ص/121، 1368ه، مطبعة الحجازي، القاهرة.

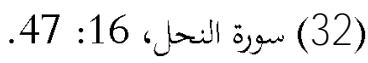

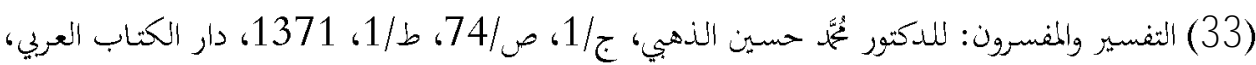

$$
\text { (34) فضائل القرآن: لأبي عبيد، ص/606. }
$$

(35) المنخول من تعليقات الأصول: للغزالي، ص/156، 1966م، تحقيق: ثمئم حسن هيتو، طبع دمشق.

$$
\text { المستصفى: للغزالي، ج/1، ص/10/، 1324ه، طبع الأميرية. }
$$

(37) البحث النحوي عند الأصوليين، للدكتور مصطفى جمال الدين، ص/43-53، ط/21، 1405هـ، دار

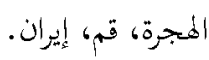

$$
\text { ) شرح المفصل: لابن يعيش، ج/1، ص/8/8 عالم الكتب، بيروت. }
$$

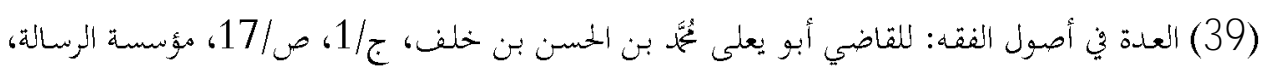

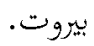

(40) أسايب الطلب عند النحويين والبلاغيبن: الدكتور قيس بن اسماعيل الآلوسي، ص/73، مطبوعات

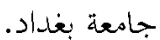

(41) عروس الأفراح فن شرح نلخيص المفتاح: لابي حامد أممد بن علي السبكي، ج/1، ص:173، ط/1،

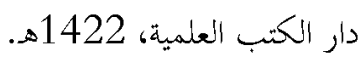

